\title{
DESALENTO: EFEITO DE SENTIDO DA OFENSIVA NEOLIBERAL SOBRE O TRABALHO'
}

\author{
SÓSTENES ERICSON² \\ Faculdade de Letras, Campus A.C. Simões, Universidade Federal de Alagoas \\ Av. Lourival Melo Mota, S/N, Tabuleiro do Martins - 57072-970 - Maceió,AL - Brasil \\ sericson1@hotmail.com
}

\begin{abstract}
Resumo. $O$ antagonismo capital-trabalho é pressuposto fundamental desta análise que versa sobre os efeitos de sentido da ofensiva neoliberal, materializados no discurso. A partir de Michel Pêcheux, tomamos o desalento, enquanto expressão, que materializa na língua as transformações contemporâneas do mercado de trabalho. Esta face oculta do desemprego é substantiva no estado de quem se mostra sem alento, aqui identificado um mecanismo discursivo parafrástico alentotrabalho. Recuperamos materialidades extraídas de reportagens que circularam na mídia, para desvelar como as práticas de linguagem são afetadas pelo acirramento da ofensiva neoliberal, tomando o desalento como expressão referencial na cena contemporânea do trabalho no Brasil.
\end{abstract}

Palavras-chave: discurso; trabalho; neoliberalismo; desalento.

\begin{abstract}
The capital-work antagonism is a fundamental presuposition of this analysis that deals about the sense effects of the neoliberal offensive, materialized in the discourse. From Michel Pêcheux, we take the discouragement, as an expression, that materializes in the language the contemporary transformations of the work market. This hidden face of unemployment is substantive in the state of being shown to be breathless, here identified a paraphrastic discourse mechanism couragement-work. We recovered materialities extracted from reports circulated in the media to reveal how language practices are affected by the intensifications of the neoliberal offensive, taking discouragement as a reference expression in the contemporary work scene in Brazil.
\end{abstract}

Keyword: discourse; work; neoliberalism; displacement.

\section{INTRODUÇÃO}

A "evidência" do discurso neoliberal (GUILBERT, 2011) põe em perspectiva os elementos de saber que o sustentam e fazem circular determinados sentidos, considerando os interdiscursos com os quais se filia e as formações ideológicas em presença.

\footnotetext{
${ }^{1}$ Uma versão inicial deste trabalho foi apresentada no Encontro ABRALIN 50, evento realizado em Maceió, em maio de 2019.

${ }^{2}$ Doutor em Letras e Linguística pela UFAL. Docente no Programa de Pós-Graduação em Linguística e Literatura (PPGLL) da UFAL.
} 
Assumindo a metáfora do edifício proposta por Marx e Engels (2001), partimos do antagonismo capital $\mathrm{x}$ trabalho, ou seja, da infraestrutura da sociedade capitalista, para, a partir daí, considerar a produção de sentidos e seus efeitos no complexo da linguagem, no discurso. Estamos considerando, então, o discurso enquanto mediação entre o trabalho e o conjunto da sociedade, na indissociabilidade entre a infra e a superestrutura. Com base nesse pressuposto, buscamos desvelar como as práticas de linguagem são afetadas pelo acirramento da ofensiva neoliberal, tomando o desalento como expressão referencial na cena contemporânea do trabalho no Brasil.

Seguindo os procedimentos apresentados por Courtine (2006), definimos como campo referencial o discurso neoliberal, em circulação no espaço midiático, com especial atenção ao desalento, tomado enquanto expressão do que nomeamos por formação discursiva (FD) do desemprego. Para o referido autor (2009), o corpus é definido como um conjunto de sequências discursivas (SD) orais ou escritas de dimensão superior à frase, extraído de um campo discursivo determinado. Nosso corpus de análise é composto por sequências discursivas extraídas de reportagens de veículos diversos, disponíveis em versão eletrônica. Estamos considerando que os recursos disponibilizados pela mídia, já são gestos de interpretação da própria mídia, "antes de se constituírem gestos de interpretação do analista, [...] na medida em que resultam de recortes seletivos relacionados a injunções na ordem do dizer/mostrar" (CAZARIN; RASIA, 2014, p. 197).

Recorremos a Pêcheux, para considerar que as condições de produção do discurso são "determinações que caracterizam um processo discursivo, inclusive as características múltiplas de uma situação concreta que conduz à produção do sentido linguístico" (PÊCHEUX; FUCHS, 1997, p. 183), uma vez que o sentido vai além de sua materialidade linguístico-sintática. No dizer de Courtine (2016), a relação entre a materialidade linguística de uma sequência discursiva e as condições históricas que determinam sua produção é regulada pelas condições de produção do discurso, que funda, assim, os procedimentos de constituição de corpus discursivos. As materialidades discursivas aqui analisadas remetem "às condições verbais de existência dos objetos (científicos, estéticos, ideológicos...) em uma conjuntura histórica dada" (PÊCHEUX, 2011, p. 152-153, grifo do autor).

Os sentidos produzidos, em condições de produção dadas, decorrem da imbricação de dois componentes: intradiscurso e interdiscurso. Tais componentes são submetidos aos efeitos ideológicos dentro das formações discursivas. Ainda de acordo com Pêcheux, uma formação discursiva é "aquilo que, numa formação ideológica dada, determinada pelo estado da luta de classes, determina o que pode e deve ser dito (articulado em forma de uma arenga, de um sermão, de um panfleto, de uma exposição, de um programa etc.)" (PÊCHEUX, 2009, p.147), sendo estes os pressupostos teórico-metodológicos que sustentam a presente análise, ancorada na teoria materialista do discurso.

\section{DESALENTO - ACONTECIMENTO ENUNCIATIVO E PROCESSOS DE SUBJETIVAÇÃO}

Assumindo a tese da crise estrutural do capital, temos em conta que esta possui um caráter destrutivo e afeta todas as esferas de atividades e o conjunto das relações humanas. Depreende-se daí que “[...] o capitalismo experimenta hoje uma profunda crise, 
impossível de ser negada por mais tempo, mesmo por seus porta-vozes e beneficiários" (MÉSZÁROS, 2009, p. 32), e que, simultaneamente, "a intervenção estatal direta no processo de reprodução capitalista fracassa, em todos os sentidos, constrangendo o curso do desenvolvimento econômico civil" (idem, p. 33).

No prelúdio histórico da crise estrutural, Long (1953) introduziu, pelo viés econômico, a designação desalento, entendendo-o enquanto fenômeno agudizado em momentos de recessão, quando trabalhadores/as desempregados/as optam por deixar de procurar emprego, o que provoca uma queda na taxa de participação na força de trabalho, a exemplo do que tem sido observado no Brasil, onde, de acordo com o Instituto Brasileiro de Geografia e Estatística (IBGE), em maio de 2018, faltava emprego para 27,7 milhões de brasileiros/as.

Todavia, face à suposta homogeneidade na categorização das pessoas desempregadas, outros sentidos são produzidos a partir das condições que marcam na língua suas distinções e particularidades. É nesse espaço que alguns dizeres vão sendo constituídos ou retomados, tendo por ancoragem a subutilização da força de trabalho, ou o que dela escapa.

A identificação de trabalhadores/as como sub/des/empregados/as, considerando a distinção geral entre os/as desempregados/as (que não têm trabalho algum, procuraram trabalho nos últimos 30 dias ou irão iniciar um trabalho imediatamente) e os/as subocupados/as (que têm vontade de trabalhar, mas trabalham menos de 40 horas semanais), mostra-se insuficiente para dar conta das transformações atuais. Nesse sentido, como tentativa de designar as pessoas que escapam dessa condição (sub/des/empregados), retoma-se a expressão desalento, conforme identificamos na SD a seguir:

SD1 - Desalento: brasileiros sem emprego desistem de procurar trabalho. São 4,3 milhões de trabalhadores vencidos pelo desânimo. IBGE pela primeira vez inclui o desalento em pesquisa. (Globo.com/Jornal Nacional, 23/02/2018)

O desalento, face oculta do desemprego, por sua vez, é substantivo no estado de quem se mostra sem alento, "trabalhadores vencidos pelo desânimo". Identificamos aqui um mecanismo discursivo parafrástico alento-trabalho, produtor da adjetivação que daí decorre por antinomia - desalentado/a, distinguindo-a de desempregado/a. A tentativa de conceituar o desalento desliza para uma oração explicativa voltada à distinção entre os/as brasileiros/as sem emprego e os/as que desistiram de procurar trabalho. Tal distinção já teria por pressuposto que no conjunto de brasileiros/as há os/as que estão sem emprego. Neste caso, a restritiva "os que" possibilita identificar o funcionamento de outro deslizamento, desta vez da base econômica (emprego - desemprego) para a esfera subjetiva, agora silenciada pelos elementos de saber que vão compondo o sentido da designação (desistem, vencidos, desânimo), alinhados ao fracasso individual.

Para produzir evidência da importância desse fenômeno, instituições como o IBGE são convocadas para apresentar dados (pesquisas) que sustentem o argumento da necessidade de enfrentamento individual da referida problemática, ao que poderia se supor que não desistir e não desanimar seriam os ingredientes necessários para não se deixar vencer. Vejamos, por exemplo, que em francês, a expressão découragement, e em Inglês 
discouragement, põe por antinomia a coragem daqueles/as que procuram por emprego, das pessoas que trabalham, alinhando o que se contabiliza como força de trabalho disponível e ocupada, bem como desempregados/as e subocupados/as.

$\mathrm{Na}$ SD1, a expressão "pela primeira vez" carrega um efeito inaugural, que simula, pela temporalidade imediata, o processo econômico-social no qual o desalento é forjado, bem como personifica o IBGE, que assume a decisão de incluir, silenciando as condições objetivas da inclusão, sobretudo se considerarmos o reordenamento do mercado de trabalho no país e o peso de 4,3 milhões de desalentados/as, que sem produzir trazem consequências também para as suas famílias e para o consumo, por exemplo.

No processo de deslocamento, a luta passa a ser não contra o desemprego, mas contra o desânimo que acaba vencendo brasileiros/as sem emprego, resultando no desalento. Observa-se aí o modo como a designação faz funcionar um mecanismo que, por paráfrase, desloca a gênese das expressões decorrentes do antagonismo capital $x$ trabalho da esfera econômica, para em seu lugar produzir sentidos de uma luta individual no mercado de trabalho, em que no imediato o/a trabalhador/a deve lutar contra o seu desânimo, e vencêlo. Tem-se, então, no horizonte uma vitória individual, conquistada a partir do que se define como elementos de saber de superação, gênese de um discurso empreendedor, interdiscurso em funcionamento no necessário silêncio (ORLANDI, 1993) que o requisita, conforme podemos identificar na $\mathrm{SD} 2$ :

SD2 - O Instituto Brasileiro de Geografia e Estatística (IBGE) considera como desempregado todo aquele que não tem trabalho, mas está à procura. Existe, no entanto, outro grupo igualmente numeroso. São brasileiros que procuraram, procuraram, mas que acabaram desistindo de encontrar. Estamos falando de 4,3 milhões trabalhadores vencidos pelo desânimo, pelo desalento. (Globo.com/Jornal Nacional, 23/02/2018)

Na SD acima, tem-se a identificação de um espaço de significação entre empregado e desempregado e na conceituação desse último, para o IBGE, como "todo aquele que não tem trabalho, mas está à procura", faz-se a conceituação também do que não pode ser designado como desempregado. Trata-se do "outro grupo igualmente numeroso", composto por "brasileiros que procuraram, procuraram, mas que acabaram desistindo de encontrar", não sendo, portanto, capazes de superar as eventuais dificuldades da insistente procura.

Por esta via, observa-se um funcionamento da oração adversativa que também pode produzir um efeito de adição:

1. Todo aquele que não tem trabalho, mas [e] está à procura.

2. Brasileiros [Todo aquele que não tem trabalho] que procuraram, procuraram, mas que [e] acabaram desistindo de encontrar [ ].

A distinção entre os brasileiros com trabalho e sem trabalho faz lançar um olhar sobre o último grupo e nele identificar uma distinção que funciona ao contrário da lógica, pois o que se espera de quem está sem trabalho é que procure trabalho. No imaginário social, a figura de quem não "quer" procurar trabalho joga com um sentido pejorativo do "desocupado", alinhado à figura do preguiçoso, oposto, portanto, a quem pretende ter sucesso no mercado de trabalho. A repetição do verbo procurar, conjugado no passado, 
por sua vez, aponta para um processo temporal que marca, para além da suposta insistência em procurar, a desistência "pelo desânimo, pelo desalento". Por esta via, o movimento parafrástico põe em relação desemprego - desalento, como também trabalho -alento.

De acordo com Zoppi-Fontana (2003, p. 250), "a análise das famílias parafrásticas que se estabelecem entre as formulações permite delimitar, a partir (entre outros) dos processos de designação, as posições de sujeito que configuram os enunciados." Por esta razão, entendemos que "se os processos discursivos constituem a fonte da produção dos efeitos de sentido no discurso, a língua, pensada como uma instância relativamente autônoma, é o lugar material onde se realizam os efeitos de sentido" (COURTINE, 2016, p. 15).

Por esta razão, estamos considerando o desalento enquanto efeito de sentido, produzido na fratura emprego-desemprego, em sua insuficiente capacidade de significar o que dela escapa. Esta noção se aproxima da formulação desenvolvida por Indursky (2008, p. 2829), ao distinguir o acontecimento discursivo (PÊCHEUX, 2008) do acontecimento enunciativo, afirmando que o segundo

[...] implica apenas a instauração de uma nova posição-sujeito no interior de uma mesma FD. Dito de outra maneira: surge aí uma nova fragmentação em relação à forma-sujeito, ou seja, surge aí um novo modo de enunciar os sentidos desta formação discursiva, mas este novo modo não opera pelo viés da ruptura com a formação discursiva e com a forma-sujeito. [...] Surgem novos saberes no interior da mesma FD.

Teríamos então um processo de designação, caracterizado por um acontecimento enunciativo constituído por antinomia, sendo produzido no deslocamento de emprego des/subemprego para emprego - desalento, sem produzir uma ruptura com a FD do desemprego. Tal relação produz na língua as condições de subjetivação que possibilitam distintas posições-sujeito, numa dada formação discursiva. Cabe ressaltar, no entanto, que os processos de identificação são "um movimento contraditório de reconhecimento/desconhecimento do sujeito em relação às determinações do inconsciente e da ideologia que o constituem, materializadas nos processos discursivos" (ZOPPI-FONTANA, 2017, p. 64).

Identificamos aí também o que Guimarães (1995) considerou como "relações de referência instáveis", produzidas pelo cruzamento de diferentes posições-sujeito, uma vez que os processos discursivos conduzem à construção de modalidades de identificação, pela interpelação ideológica, constituindo "o sujeito do discurso, a partir de sua inscrição no simbólico e na história" (ZOPPI-FONTANA, 2017, p. 64). Nesta perspectiva, as relações entre os diferentes dizeres assumem contornos expressivos das posições-sujeito, o que permite inferir que os processos de identificação com uma dada FD têm base nas filiações ideológicas, razão pela qual é possível apontar os dizeres que os reproduzem, a exemplo do que observamos a seguir:

SD3 - Se este conceito soa um pouco abstrato, vai um exemplo concreto: depois de cinco anos trabalhando como auxiliar administrativa na mesma empresa, Mayara foi demitida em 2016; passou 2017 inteiro fazendo entrevista de emprego e nada. " 15 entrevistas e nada, nada, nada, nada. Não tive retorno de nada. No momento desisti. Murro em ponta de faca é o que 
a gente está dando", disse Mayara da Rocha. (Globo.com/Jornal Nacional, 23/02/2018)

A tentativa de exemplificar requisita trazer dizeres de um sujeito empírico para traduzir no relato individual aquilo que os números, supostamente, não conseguem dizer ao leitor que considera o conceito de desalento "um pouco abstrato". Inicialmente, o site Globo.com busca os dados de pesquisa do IBGE para sustentar a argumentação do que procura pôr em evidência na imediaticidade do dizer - o aumento do número de desalentados no Brasil. Todavia, em seguida, desloca-se do espaço argumentativo da pesquisa (IBGE) para trazer a voz de uma mulher trabalhadora desempregada, que por haver desistido de procurar emprego, estava agora sendo um exemplo de pessoa desalentada.

Interessante notar o mecanismo de repetição que estava presente na SD2 (procuraram, procuraram) e agora comparece na negativa (nada, nada, nada, nada). A negativa se opõe ao retorno que se espera para quem fez 15 entrevistas de emprego, produzindo uma relação de consequência, como "não tive retorno de nada", "desisti". Não menos importante, em se tratando de um processo que é recuperado pela reportagem ("depois de cinco anos trabalhando como auxiliar administrativa na mesma empresa, Mayara foi demitida em 2016; passou 2017 inteiro fazendo entrevista de emprego e nada"), é observar no recorte temporal um momento específico da história brasileira, no qual um golpe político-jurídico foi desenvolvido por segmentos conservadores, em consonância com os principais representantes do capital financeiro, nacional e internacional.

Nesse período de crescimento do desemprego, são contados em milhões os brasileiros e as brasileiras que estão "fazendo entrevista de emprego e nada". O advérbio "nada" passa, então, a representar na língua o resultado da busca frustrada por emprego, para uma parcela significativa da classe trabalhadora no Brasil. Do ponto de vista de classe, opera um deslizamento do "não tive" e "desisti" para "murro em ponta de faca é o que a gente está dando". Do eu (mulher brasileira desempregada que desistiu de procurar emprego) para o a gente, enquanto representação de milhões que se encontram na mesma situação (desalentados/as), aponta-se para um dito popular que representa um sentimento característico: dando murro em ponta de faca, ou seja, insistindo em algo sabendo que não vai conseguir. Trata-se, portanto, da desesperança, elemento de saber oposto ao que se constitui no discurso do empreendedorismo e do sucesso individual.

Todavia, como ainda se pode resistir, observa-se um efeito de temporalidade que indica haver outras possibilidades - "no momento". A brevidade aí indicada abre margem para considerar que é possível, pelo menos, ser chamada para entrevista. Esse caráter momentâneo, por sua vez, pode contribuir para o silenciamento (ORLANDI, 1993) do desemprego estrutural, como algo constitutivo do modo de produção capitalista, tendo em vista o indispensável "exército industrial de reserva" e sua relação com a disponibilidade de força de trabalho, valor dos salários, legislação trabalhista etc.

$\mathrm{Na}$ reportagem citada, no entanto, a entrevistada não assume um dizer de si enquanto desalentada, sendo a designação atribuída com base nas noções que a distinguem nas posiçõessujeito na FD do desemprego. A filiação com esta FD se dá, então, através de mecanismos ideológicos e inconscientes, sendo interessante ter em conta, conforme Zoppi-Fontana (2017, p. 64) afirma, que 
a contradição constitutiva dos processos de produção de sentido e do sujeito, que tanto reforçam o imaginário social quanto irrompem como acontecimento, abrindo brechas sociais e discursivas para $\mathrm{o}$ deslocamento de sentidos e a emergência de novas modalidades de subjetivação.

Um dizer sobre o desalento, em posição de voz autorizada, leia-se um lugar de autoridade conferido pelo estatuto científico e institucional, também é requisitado e, desta vez, situa a possível causa do fenômeno na esfera econômica, sem, contudo, explicar as suas condições estruturais e o papel do Estado na sua (re)produção, conforme verificamos na próxima SD.

SD4 - "Isso pode estar relacionado principalmente com esta crise econômica, onde a desocupação é alta e as pessoas acreditam que elas podem não conseguir trabalho e acabam se afastando da força de trabalho", explicou Cimar Azeredo, coordenador de trabalho e rendimento do IBGE. (Globo.com/Jornal Nacional, 23/02/2018)

No necessário afastamento do falante e na proximidade do interlocutor, o pronome demonstrativo "isso", em sua referência ao anteriormente mencionado, encerra na singularidade que o constitui a complexidade das expressões que representa. Abrindo possibilidade para outras relações, além da crise econômica, é assumida uma posição que reconhece a relação do desalento "principalmente com esta crise econômica". Situando no campo das crenças pessoais ("as pessoas acreditam"), resgata-se uma relação causa-efeito, na qual a alta desocupação leva as pessoas a acreditarem que não podem conseguir trabalho e desse modo "acabam se afastando da força de trabalho". Esse afastamento conduzido pelas próprias pessoas põe em perspectiva, novamente, a responsabilidade individual, ao tempo em que traz uma noção de força de trabalho como mercado de trabalho, como se o/a próprio/a trabalhador/a não fosse ele/a mesmo/a a força de trabalho, a estar disponível para ser vendida ao capitalista.

Cabe ressaltar que uma associação do desalento com a crise econômica no Brasil já havia sido apontada em 2015, também no Globo.com, quando as pesquisas do IBGE apontaram uma taxa de desemprego de 7,5\%, com tendência crescente. Quer tomando como referência dados de pesquisa sobre mercado de trabalho, quer "por qualquer ponto de vista", as evidências demonstravam ali o aumento do processo de demissões, o que de fato se confirmou nos anos seguintes.

SD5 - A crise e o desalento dos trabalhadores. Por qualquer ponto de vista ou metodologia sobre os dados do mercado de trabalho, não há nada que indique estancamento ou até mesmo arrefecimento do processo de demissões em curso. Com um resultado acima do esperado pelos analistas do mercado financeiro, a taxa de desemprego do IBGE ficou em 7,5\% em julho. Mais surpreendente do que o número geral foi a alta de $56 \%$ no número de desempregados no mês passado, em comparação com o mesmo período em 2014. Um recorde, nunca antes visto pelos analistas do Instituto. (Globo.com/Thais Herédia, 20/08/2015)

No início da SD5, a construção do enunciado não distancia a crise (econômica) do desalento dos trabalhadores, antes traz a crise primeiro e a considera no singular, embora não especifique de que crise se trata. Um olhar mais atento vai identificar, entretanto, que os dizeres a seguir 
dão conta de descrever o cenário do desemprego num determinado período histórico. Dessa maneira, uma vez não adjetivada, a crise torna-se relacionada ao desemprego e não aos fundamentos do projeto neoliberal em sua face mais recente, considerando a realidade brasileira. Vê, portanto, que o embate continua localizado na esfera econômica, mas reduzido à oferta de emprego e não à crise estrutural do capital, que impõe, entre outras estratégias, o reordenamento das forças produtivas. Tem-se, então, um percentual de desemprego que excede aos níveis razoáveis, ou em outras palavras, que se situa "acima do esperado pelos analistas do mercado financeiro".

Convém observar que há um dizer distinto dos até então analisados. Nas SD anteriores, o desalento comparecia enquanto adjetivo dos/as trabalhadores/as. Todavia, na SD5 ocorre uma apropriação do desalento que passa não somente a produzir efeito de adjetivação, mas também de propriedade. Nesse sentido, "o desalento dos trabalhadores", diríamos o desalento dos/as trabalhadores/as desempregados/as que desistiram de procurar emprego, passa a significar uma relação de pertencimento, constituída em um processo de perpetuação e de crescimento numérico, conforme indicam os dados apresentados.

Nota-se, desse modo, que a regulação da exploração do trabalho pelo capital, não somente pelo Estado neoliberal, como pelas leis do mercado, mostra-se insuficiente para exercer o controle absoluto sobre a dinâmica de reprodução do sistema capitalista, instaurando distintas posições-sujeito, que "se constituem em um movimento contínuo de processos de identificação na história e na relação com os modos de individuação em relação à formação social e ao Estado" (ZOPPI-FONTANA, 2017, p. 65).

Considerando que o discurso neoliberal está ancorado em dizeres como "eficiência econômica", "lucratividade financeira" e "retorno sobre o investimento" (GUILBERT, 2011, p. 15) ${ }^{3}$, distinguimos daí os elementos de saber do discurso do desemprego, sendo esses então relacionados ao modo como as consequências daquele se materializam na língua. Uma vez tomados como meta "eficiência econômica", "lucratividade financeira" e "retorno do investimento", são requisitados os mecanismos e estratégias para o seu alcance, leiamos, desemprego, redução de salários, flexibilização da legislação trabalhista, entre outros. Por esta razão, "os teóricos do neoliberalismo dizem defender a livre iniciativa e o mercado contra o intervencionismo do Estado que seria um freio no mercado privado, o único produtor real da riqueza, bem-estar e até democracia" (idem, ibidem).

Nesta perspectiva, situamos o discurso neoliberal e o discurso do desemprego, aqui tomados em sua filiação constitutiva com a formação ideológica do capital (AMARAL, 2005), pondo em relevo uma necessária reciprocidade, que produz efeitos de sentido e novas posições-sujeito, nos deslocamentos e circulação de sentidos, a exemplo do que ocorre no espaço midiático. Nos termos de Courtine, (2016, p. 26), temos aí o funcionamento de um domínio de memória, em que os elementos de saber da FD de referência (FD neoliberal) dominam uma FD contraditoriamente a ela ligada (FD do desemprego), "por relações de antagonismo, escoramento, aliança, recuperação... etc....", no que o referido autor conceituou como a "pluralidade contraditória" de sequências discursivas, caso da antinomia trabalho - desalento.

\footnotetext{
${ }^{3}$ As citações do referido autor são de nossa tradução.
} 


\section{DESALENTO: DESLOCAMENTOS E CIRCULAÇÃO DE SENTIDOS}

Neste trabalho, partimos do pressuposto de que o contato entre o ideológico e o linguístico é materializado no discurso, "na medida em que ele representa no interior da língua os efeitos das contradições ideológicas e onde, inversamente, manifesta a existência da materialidade linguística no interior da ideologia" (COURTINE, 2016, p. 14) e pressupõe a existência e o funcionamento de diversos fios ideológicos e discursivos, que atuam de modo constitutivo e indissociável nos processos de produção e circulação de sentidos, considerando a atuação do interdiscurso.

Ainda de acordo com Courtine (2016, p. 23), “o interdiscurso de uma FD, como instância de formação/repetição/transformação dos elementos do saber daquela FD, pode ser referido como aquele que rege o deslocamento de suas fronteiras". Por sua vez, as retomadas e os deslocamentos constituem o funcionamento da memória discursiva, contribuindo para a formulação e repetição de dizeres, como também para o seu silenciamento (ORLANDI, 1993). Basta lembrar que a ideologia neoliberal e o discurso neoliberal baseiam-se no conceito de rentabilidade de curto prazo e no arcabouço matemático e econômico geral para produzir a eficiência tópica, voltada para a rentabilidade financeira (GUILBERT, 2011), embora nem sempre esses elementos de saber estejam materializados na superfície discursiva da FD neoliberal.

Nessa perspectiva, para a produção e circulação de sentidos, o discurso neoliberal faz funcionar uma memória discursiva que reforça seus efeitos e para tanto conta com a mídia e com grandes organizações internacionais, como Fundo Monetário Internacional (FMI), Banco Mundial, Agência de Cooperação e Desenvolvimento Econômico (OCDE), União Europeia, entre outros (GUILBERT, 2011).

Um investimento no resgate do percurso temático da FD neoliberal possibilita identificar, no dizer de Rosa (2008, p. 30, grifos do autor), que

a ortodoxia fundacional do discurso neoliberal foi fixada no âmbito da Sociedade de Mont Pèlerin, principalmente em face das contribuições de Hayek e Friedman. A obra 'The Road to Serfdom' pode ser apontada como o texto fundador, uma vez que, como texto político, promove uma crítica ao modelo do 'Bem Estar Social' surgido no pós Segunda Guerra Mundial. Pretende demonstrar os prejuízos de uma estrutura organizada e centralizada pelo Estado Intervencionista e tutor de Direitos Sociais. Aponta os benefícios coletivos a partir do interesse individual que se pode obter quando o 'mercado' funciona adequadamente.

É nesse processo de constituição do ideário neoliberal que o chamado Consenso de Washington ${ }^{4}$ propõe como receita para os efeitos da crise estrutural do capital na América Latina, disciplina fiscal, redução de despesa pública, liberalização das bolsas e mercados financeiros, privatizações, proteção dos direitos de propriedade e desregulamentação (GUILBERT, 2011), que são aqui considerados como elementos de saber do discurso neoliberal, silenciados na SD a seguir.

\footnotetext{
${ }^{4}$ Noção formulada por Williamson em 1990, para designar "os pontos comuns a todas as reformas prescritas como remédios para as dificuldades financeiras da América Latina” (GUILBERT, 2011, p. 20).
} 
SD6 - Frustração com políticos e governo dá o tom no primeiro dia de discussões do Fórum Nacional, no Rio. Desalento com corrupção domina fórum. O desalento com a política e a corrupção permeou ontem a abertura da $18^{\circ}$ edição do Fórum Nacional, tradicionalmente dedicado ao debate da conjuntura e do futuro econômico do país. (Folha de S. Paulo/Debate Econômico, $16 / 05 / 2006)$

A referida SD foi extraída de um veículo de grande circulação nacional, no período marcado pelo chamado escândalo do mensalão, envolvendo diversos partidos políticos na compra de votos de parlamentares do Congresso Nacional, durante o primeiro mandato do governo Lula/PT. Interessa observar que o referido Fórum reuniu representantes de diversos setores da economia, de instituições financeiras, e de outros segmentos, como da justiça, a exemplo do jurista Miguel Reale Júnior, com o objetivo de debater a conjuntura e o futuro do país.

No deslocamento para outra FD, tem-se a retomada da expressão referencial desalento funcionando como reação, dos segmentos ali representados, contra os políticos, o governo Lula e a corrupção. O sentido de desalento, no entanto, desloca-se do que vimos analisando até agora, apontando para a formulação de dizeres que parecem produzir um distanciamento da cena política da época, ao tempo em que não pode prescindir dela, tendo em conta que estava em perspectiva o processo eleitoral.

Não custa afirmar que a expressão desalento produz um deslize de sentido, na medida em que as pesquisas da época, a despeito do referido escândalo, apontavam para o favoritismo do então presidente Lula à reeleição, o que acabou se confirmando com a sua vitória em segundo turno, contra o candidato Geraldo Alckmin/PSDB. Trata-se, então, de considerar o desalento de um segmento da classe dominante com relação aos rumos políticos e econômicos do país, ainda que isso não tenha resultado em desistência, a exemplo do projeto que ganhou fôlego nos anos seguintes, culminando com o golpe de 2016.

Nesse sentido, observamos um deslizamento da expressão desalento entre as distintas FD, produzindo sentidos diversos do que apresenta na sua filiação à FD do desemprego. Todavia, o que interessa considerar é como, no dizer de Zoppi-Fontana (2017, p. 66),

os lugares de enunciação, por presença ou ausência, configuram um modo de dizer (sua circulação, sua legitimidade, sua organização enunciativa) e são diretamente afetados pelos processos históricos de silenciamento. Esses modos de dizer mobilizam as formas discursivas de um eu ou um nós, de cuja representação imaginária a enunciação retira sua legitimidade e força performativa.

O deslocamento do desalento para a esfera do debate político, contudo, silencia que sua gênese estava voltada para a esfera econômica e pelo funcionamento ideológico é possível apontar alguns elementos que sustentam sua filiação com o ideário neoliberal. É oportuno citar, por exemplo, que no Fórum Nacional, o professor José Murilo de Carvalho/UFRJ, em sua exposição sobre a necessária revolução da cidadania (!), "atacou duas visões caras ao PT e ao governo Lula: a aposta na ação dos movimentos sociais - 'um erro' - e o orçamento participativo, cujos resultados 'foram, na melhor das hipóteses, ambíguos"” (Folha de S.Paulo, Debate Econômico, 16/05/2006). 
Concordamos, então, com Zoppi-Fontana (2017, p. 66), quando ela afirma:

se é a posição-sujeito que determina os sentidos dos enunciados a partir do funcionamento da memória discursiva, é na enunciação de um sujeito em determinadas condições de produção que esse dizer poderá ser reconhecido como legítimo relativamente a um determinado lugar enunciativo.

Não está em causa, portanto, se os segmentos ali representados estavam ou não desalentados, mas o modo como uma dada posição-sujeito, situada em determinadas condições de produção do discurso, determina o sentido do enunciado desalento, fazendo funcionar, pela ideologia, que se trata de desalento na esfera política, silenciando o antagonismo de classes e a ameaça aos interesses neoliberais com o avanço das políticas sociais. No jogo da cena enunciativa do discurso político (ERICSON, 2019) ganha fôlego o desalento com a corrupção e seus desdobramentos recentes atestam para a eficácia dos seus efeitos.

De acordo com Mészáros (2008, p. 14), sob as condições de aprofundamento da crise estrutural do sistema do capital, os problemas do Estado tornam-se, inevitavelmente, cada vez maiores. Pois, na forma há muito estabelecida do processo de tomada de decisão política global, o Estado deveria proporcionar a solução para os vários problemas que obscurecem nosso horizonte, mas não consegue fazê-lo.

Face ao avanço da ofensiva neoliberal e em função do recuo do Estado, a dinâmica do mercado de trabalho vai assumindo novos contornos, de acordo com o controle sociometabólico do capital (MÉSZÁROS, 2009). Nessas condições, o aumento do desemprego (acima do esperado pelos analistas do mercado financeiro/SD5) torna-se uma preocupação momentânea para a esfera da produção, repercutindo também na circulação e no consumo, nas mais diversas cadeias produtivas. Além disso, ainda é preciso levar em consideração o aumento do número de pessoas que desistiram de procurar emprego.

O IBGE apontou que o número de desalentados/as passou de 1,5 milhão no segundo trimestre de 2014 (menor número desde o início da série em 2012), para 4,8 milhões em agosto de 2018. De acordo com o Instituto de Pesquisa Econômica Aplicada (IPEA), 59\% dessas pessoas moram no Nordeste, $54,3 \%$ são mulheres, $50 \%$ não concluíram o ensino fundamental, quase $70 \%$ não são chefes de família e a maioria é composta por jovens adultos (de 18 a 24 anos).

Essa estratificação do desalento mostra uma caracterização que nos permite considerar não só a sua complexidade, enquanto fenômeno contemporâneo do mercado de trabalho no Brasil, como também o seu caráter heterogêneo. Desse modo, observa-se uma imbricação interseccional de gênero, classe social, região e geração. Para estes/as, a busca por trabalho consistiria um gesto último de resistência dos sujeitos face ao rebaixamento do salário esperado e da probabilidade de conseguir uma vaga no mercado e, ao mesmo tempo, um momento que antecede o seu desalento.

Não está em questão o rebaixamento dos salários, por exemplo, ou a desproporção salarial entre gêneros. Chegamos a um ponto em que o aumento acelerado de desemprego e a diminuição na geração de novas vagas de trabalho faz crescer um excedente no já 
considerado "exército de reserva", corroborando com a afirmação de Marx (2001, p. 154), para quem:

o significado que a produção tem em relação aos ricos revela-se no sentido que ela tem para os pobres; em cima, a sua manifestação é sempre refinada, oculta, ambígua, uma aparência; em baixo, é sempre uma realidade tosca, simples, cândida.

Em condições de pauperismo, já não importa que "o salário é determinado pela luta árdua entre o capitalista e o trabalhador. O necessário triunfo do capitalista" (MARX, 2001, p. 65). As condições objetivas capturam a subjetividade de trabalhadores/as, produzindo um sentido de alento a quem ainda está vendendo a sua força de trabalho. Observa-se, portanto, que "o trabalhador se afunda no pauperismo, e este cresce mais rapidamente do que a população e a riqueza" (MARX; ENGELS, 2001, p. 64). Conforme demonstrado na análise feita pelos referidos autores, "a burguesia é incapaz de cumprir o papal de classe dominante e de impor à sociedade, como lei suprema, as condições de existência de sua classe" (idem, ibidem). Considerando que "a condição de existência do capital é o trabalho assalariado" (MARX; ENGELS, 2001, p. 64), o par exploração/alento torna-se possível, na contradição que o constitui.

A tensão instalada, e de algum modo aqui repercutida, considerando que a maioria das materialidades analisadas fazia referência ao desalento dos trabalhadores, fez-nos observar como outras marcas linguístico-discursivas eram consideradas nos processos de designação, considerando, a exemplo do que apresentamos, que as mulheres comparecem em maior número entre as pessoas desalentadas.

SD7 - O desalento das pessoas que desistiram de procurar trabalho. (Revista Retratos, 01/06/2018).

Tem-se aí uma construção que se assemelha com o que apresentamos na SD5 (o desalento dos trabalhadores), todavia, por substituição, trabalhadores e pessoas são tomados como sinônimos, num movimento que aponta para uma particularidade que o substantivo masculino plural "trabalhadores" não possibilita identificar. A restritiva "pessoas que" requisita um complemento necessário à formulação da noção de desalento, enquanto núcleo significante, relacionando-o à desistência de procurar trabalho. Entretanto, a reportagem apresenta como exemplo os casos de duas mulheres jovens, estudantes e residentes em Salvador, "que têm em comum, além da idade (23 anos), o mesmo sentimento em relação ao mercado de trabalho: o desânimo" (Revista Retratos, 01/06/2018).

Desalento e desânimo são tomados por sinônimos, na tentativa de apreender, pela subjetividade, as expressões mais violentas do mercado de trabalho sobre a população desempregada. As experiências apresentadas na reportagem contribuem para a reprodução de dizeres que, por repetição, produzem efeitos de sentido do engajamento pessoal ou da desistência, ao tempo em que possibilitam os processos de subjetivação dos sujeitos na FD do desemprego, conforme citado por uma das entrevistas: "durante todo esse tempo coloquei uns 60 currículos. Quando eu via que ninguém me chamava para entrevista eu desanimava e desistia, depois tentava de novo. Mas em agosto de $2017 \mathrm{eu}$ decidi parar de procurar" (Revista Retratos, 01/06/2018). 
Numa relação que se estabelece entre um eu (coloquei, eu via, me chamava, eu desanimava, desistia, tentava, eu decidi) e um ninguém (ninguém me chamava), há um funcionamento de representações imaginárias que reforçam para o sujeito da referida FD que a possibilidade de desistir está em suas mãos, simulando certa autonomia face às condições objetivamente postas - "durante todo esse tempo coloquei uns 60 currículos. Quando eu via que ninguém me chamava para entrevista". A precisão da data (agosto de 2017) põe em destaque, por sua vez, o efeito da decisão de "parar de procurar".

A exemplo do que identificamos na SD2 (desistindo de encontrar [trabalho]), aqui temos um enunciado que não cita a palavra trabalho, deixando em aberto o que decidiu "parar de procurar". Esse espaço, no entanto, compromete o interlocutor na cena enunciativa, podendo trazer implicitamente o trabalho, como também podendo fazer funcionar formas diversas de exploração, que não as requisitadas com "uns 60 currículos".

Infelizmente, o perfil das jovens de Salvador tem sido recorrente em outras regiões do país, conforme observamos na SD8:

SD8 - Jovens, pouco experientes e desalentadas. Em Minas Gerais,
Indira de Oliveira, 24 anos, desistiu de procurar emprego e, por conta
disso, também teve que desistir de casar e construir seu próprio lar.
Desde que a pequena empresa de telemarketing em que trabalhava
fechou, no final de 2015 , Indira não consegue uma recolocação formal
no mercado de trabalho. E não foi por falta de tentativa: entre outubro
de 2015 e novembro de 2017 a jovem contabilizou o envio de 358
currículos para a Região Metropolitana de Belo Horizonte. "Desse total,
no máximo umas 15 empresas marcaram entrevistas. Poucas
retornaram o contato", lamenta. Cansada de sofrer com a expectativa de
conseguir o emprego, ela decidiu dar uma pausa nas buscas no final do
ano passado. (PNAD contínua trimestral, $4^{\circ}$ tri, 2017)

Conforme vimos apontando em SD anteriores, as condições de produção do discurso vão compondo enunciados que apontam tanto para os elementos de saber de uma dada FD, como também para as distintas posições-sujeito em presença, e ao modo de designação. É o que verificamos nos dizeres trabalhadores (SD1, SD2 e SD5), pessoas (SD4 e SD7) e jovens desalentadas (SD8). Mesmo não havendo nenhum estudo apontando que os homens estão ocupando a maioria entre as pessoas desalentadas e ainda que as pesquisas apresentadas afirmem que são as mulheres a maioria, ocorre a reprodução de um dizer que assume caráter dominante em que as mulheres são silenciadas, em sua singularidade, na expressão "trabalhadores", recuperando do imaginário uma relação historicamente determinada entre os homens e o trabalho.

De acordo com os especialistas consultados pela Revista IstoÉ (2018), “em situação desigual no mercado de trabalho, sobretudo pela remuneração menor do que a dos homens, as mulheres também acabam desistindo de procurar um emprego com mais frequência. Elas representam 54\% dos desalentados". Não menos importante é levar em consideração o que significaria para os homens desistir, desanimar, assumir a condição de desalentados, tendo em conta o imaginário social do homem-provedor, construído em oposição ao preguiçoso, ao malandro, ao desocupado. 
Considerando os aspectos regionais, chama atenção a relação entre a distribuição regional do número de pessoas desalentadas e o perfil econômico regional. É o que podemos verificar quando se observa que o desalento é maior entre as mulheres nordestinas. "No nordeste, onde o mercado de trabalho é mais frágil, os que desistiram de procurar emprego eram 2,91 milhões em junho. Isso significa que $60 \%$ dos brasileiros que estavam no desalento moram na região" (IstoÉ, 19/08/18).

Para além do desafio histórico de superação das desigualdades regionais do Brasil, vê-se que, ao assumir a agenda neoliberal, o Estado brasileiro sedimentou os mecanismos necessários ao avanço irrefreável do capital, razão pela qual é preciso considerar, conforme Mészáros (2008, p. 164) afirmou, que

enfrentar toda a problemática do Estado envolve uma multiplicidade de determinações externas e internas em sua íntima interconectividade, nas quais o Estado é tanto o órgão geral de uma dada sociedade como representa a ligação desta com a totalidade social de sua época histórica. Consequentemente, o Estado é, em um sentido, mediação por excelência, já que articula, ao redor de um foco político comum, a totalidade das relações internas - dos intercâmbios econômicos aos laços estritamente culturais - e as integra em vários graus à estrutura global da formação social dominante.

Embora tenhamos dado realce ao cenário brasileiro contemporâneo, é bom lembrar que, ainda em 1872, Marx e Engels (2001, p. 55) já haviam afirmado que "impelida pela necessidade de mercados sempre novos, a burguesia invade o globo inteiro. É para ela uma necessidade penetrar por toda parte, estabelecer-se por toda parte, criar relações por toda parte" (p. 55). Mesmo no tocante às crises cíclicas, os referidos autores afirmaram que "cada crise destrói regularmente não só uma grande massa de produtos já fabricados, mas também uma grande parte das próprias forças produtivas" (MARX; ENGELS, 2001, p. 57). Todavia, em tempos de crise estrutural do capital, torna-se imperativo considerar que "a burguesia produz seus próprios coveiros. Sua queda e a vitória do proletariado são igualmente inevitáveis" (MARX; ENGELS, 2001, p. 64).

\section{UM EFEITO-CONCLUSÃO}

A análise aqui apresentada possibilitou demonstrar que o desalento é um efeito de sentido produzido na fratura do emprego - des/subemprego e constitui um acontecimento enunciativo, que instaura uma nova posição-sujeito no discurso do desemprego, sendo um efeito de sentido da ofensiva neoliberal sobre o trabalho.

Depreende-se daí que em tempos de crise estrutural, ser explorado/a pelo capital enquanto força de trabalho seria, portanto, um alento para o/a trabalhador/a. A superação desse sistema de opressão/exploração se coloca no horizonte e legitima a luta de classes, num projeto revolucionário em prol da construção de uma sociedade efetivamente humana, para além do capital, da propriedade privada, do Estado, da cultura patriarcal e de todas as suas consequências. Se Marx (2008, p. 14) já demonstrou "como a luta de classes na França criou circunstâncias e condições que possibilitaram a um personagem medíocre e grotesco desempenhar um papel de herói”, resta-nos, agora, assumir o desafio histórico de não desistir. 


\section{REFERÊNCIAS}

AMARAL, Maria Virgínia Borges. Discurso e relações de trabalho. Maceió: Edufal, 2005.

BRASIL. Instituto Brasileiro de Geografia e Estatística (IBGE). PNAD contínua trimestral, $4^{\circ}$ trim./2017. Disponível em https://agenciadenoticias.ibge.gov.br/agencia-noticias/2012-agenciade-noticias/noticias/21318-o-desalento-das-pessoas-que-desistiram-de-procurar-trabalho.

Acesso em 16 set 2018.

CAZARIN, E.A.; RASIA, G. dos S. As noções de acontecimento enunciativo e de acontecimento discursivo: um olhar sobre o discurso político. Letras, Santa Maria, v. 24, n. 48, 193-210, 2014.

COURTINE, Jean-Jacques. Definição de orientações teóricas e construção de procedimentos em Análise do Discurso. Policromias, ano 1, 14-35, junho/2016.

COURTINE, Jean-Jacques. Análise do discurso político. O discurso comunista endereçado aos cristãos. Trad. Bras. São Carlos: EdUFSCar, 2009.

INDURSKY, F. Unicidade, desdobramento, fragmentação: a trajetória da noção de sujeito na Análise do Discurso. Em: MITTMANN, S. et. al. (Orgas.). Práticas discursivas e identitárias: sujeito e língua. Porto Alegre: Nova Prova, 2008. p. 9-33.

ERICSON, S. Estado democrático de direito: deslocamentos e ambiguidades na argumentação. EID\&A [Revista Eletrônica de Estudos Integrados em Discurso e Argumentação], Ilhéus, n. 19, 103-120, ago.2019.

GUILBERT, Thierry. L" “évidence" du discours neoliberal: analyse dans la presse écrite. Broissieux: Éditions du Croquant, 2011.

GUIMARÃES, Eduardo R.J. Os limites dos sentidos. Campinas: Pontes, 1995.

HERÉDIA, Thais. A crise e o desalento dos trabalhadores. G1/Globo.com [Portal], 20/08/2015. Disponível em http://g1.globo.com/economia/blog/thais-heredia/post/crise-e-o-desalento-dostrabalhadores.html. Acesso em 16 set 2018.

ISTOÉ Dinheiro. Desalento é maior entre as mulheres nordestinas. 19/08/18. Disponível em https://www.istoedinheiro.com.br/desalento-e-maior-entre-as-mulheres-nordestinas/. Acesso em 16 set 2018.

JORNAL NACIONAL. Desalento: brasileiros sem emprego desistem de procurar trabalho. Globo.com, 23/02/2018. Disponível em http://g1.globo.com/jornalnacional/noticia/2018/02/desalento-brasileiros-sem-emprego-desistem-de-procurartrabalho.html. Acesso em 16 set 2018.

LIMA, A.; TALLMANN, H.; LOSCHI, M; CÁSSIA, Rita de. O desalento das pessoas que desistiram de procurar trabalho. Retratos [IBGE], 01/06/2018. Disponível em https://agenciadenoticias.ibge.gov.br/agencia-noticias/2012-agencia-de-noticias/noticias/21318o-desalento-das-pessoas-que-desistiram-de-procurar-trabalho. Acesso em: 16 set 2018.

LONG, C.D. Impact of effective demand on the labor supply. The American Economic Review, 458-467. Disponível em www.jstor.org/stable/1831509. Acesso em 1 nov. 2019.

MARX, K. O 18 Brumário de Luís Bonaparte. $2^{\mathrm{a}}$. ed. São Paulo: Matrin-Claret, 2008.

MARX, K.; ENGELS, F. Manifesto Comunista. $3^{\text {a }}$. ed. Rio de Janeiro: Garamond, 2001.

MARX, K. Manuscritos econômicos-filosóficos. $3^{\text {a }}$. reimpr. São Paulo: Matrin-Claret, 2001.

MÉSZÁROS, I. A montanha que devemos conquistar: reflexões acerca do Estado. Trad. Bras.

São Paulo: Boitempo, 2015.

MÉSZÁROS, I. A crise estrutural do capital. Trad. Bras. São Paulo: Boitempo, 2009.

ORLANDI, E.P. As formas do silêncio: no movimento dos sentidos. $2^{\mathrm{a}}$. ed. São Paulo: Editora Unicamp, 1993.

PATU, G.; BILLI, M. Desalento com corrupção domina Fórum. Folha de S. Paulo, 16 de maio de 2006. Disponível em https://www1.folha.uol.com.br/fsp/dinheiro/fil605200622.htm. Acesso em 16 set 2018.

PÊCHEUX, Michel. Análise de Discurso - Michel Pêcheux. Textos escolhidos por Eni Puccinelli Orlandi. 2a ed. Campinas: Pontes, 2011.

PÊCHEUX, M. Semântica e Discurso: uma crítica à afirmação do óbvio. Trad. Bras. $4^{\mathrm{a}}$. ed. Campinas: Pontes, 2009.

PÊCHEUX, M. O discurso: estrutura ou acontecimento. 4ª ed. Campinas: Pontes, 2006. 
ROSA, Alexandre Morais. Discurso neoliberal e Estado Democrático de Direito. Ciências Sociais Aplicadas em Revista. UNIOESTE/MCR, v. 8, n. 15, 27-40, 20 sem. 2008.

ZOPPI-FONTANA, M.G. "Lugar de fala": enunciação, subjetivação, resistência. Conexão Letras, v. 12, $\mathrm{n}^{\circ}$ 18, 63-71, 2017.

ZOPPI-FONTANA, M.G. Identidades (in) formais: contradição, processos de designação e subjetivação na diferença. Organon, 35, UFRGS, v. 17, n. 35, 245-282, 2003.

Artigo recebido em: out. de 2019.

Aprovado e revisado em: nov. de 2019.

Publicado em: dezembro de 2019.

Para citar este texto:

ERICSON, Sóstenes. Desalento: efeito de sentido da ofensiva neoliberal sobre o trabalho. Entremeios [Revista de Estudos do Discurso, ISSN 2179-3514, on-line, www.entremeios.inf.br], Seção Estudos, Programa de Pós-Graduação em Ciências da Linguagem (PPGCL), Universidade do Vale do Sapucaí (UNIVÁS), Pouso Alegre (MG), vol. 20, Especial, Dossiê "Língua, discurso e trabalho na contemporaneidade", p. 45-60, dez. 2019.

DOI: http://dx.doi.org/10.20337/ISSN2179-3514revistaENTREMEIOSvol20pagina45a60 